\title{
PENETAPAN DAYA TAMPUNG BEBAN PENCEMARAN TUKAD MATI DI KABUPATEN BADUNG DENGAN MODEL QUAL2KW 5.1
}

\author{
I Kadek Ardi Putra ${ }^{1 *}$, I Wayan Budiarsa Suyasa ${ }^{2)}$, I G B SilaDharma ${ }^{3)}$ \\ ${ }^{1)}$ Magister Ilmu Lingkungan Universitas Udayana \\ ${ }^{2)}$ Fakultas MIPA Universitas Udayana \\ ${ }^{3)}$ Fakultas Kelautandan Perikanan Universitas Udayana \\ *Email : ikadek_ardiputra@yahoo.com
}

\section{ABSTRCT \\ DETERMINATION OF THE POLLUTION LOAD CAPACITY OF TUKAD MATI IN BADUNG REGENCY USING QUAL2KW 5.1 MODEL}

Tukad Mati is one of watershed that is flow through two regencies of Badung and Denpasar that has $12 \mathrm{~km}$ length. TukadMati functioned as irrigation, drainage system and as the exile of wastewater from all activities along the river. Because of the pollution, the water quality has degraded. The source of pollution is organic matter pollutant, agricultural pollutant such as pesticide and hazardous waste. The aim of this research is knowing the pollutant loading rate from point source and non point source using Qual2kw model, to define that amount of pollutant that are allowed to exile in TukadMati river. The water quality parameter that analyzed is DO, COD, BOD and Phosphate. This research divided into three sections, and 4 scenario of simulation to know allowed loading rate of pollutant along the river. The result of simulation using Qual2kw for BOD that is the minimum DO loading rate was $1,15 \mathrm{~kg} /$ day for section 1 then maximum loading rate is $64,88 \mathrm{~kg} /$ day on section 3 . Meanwhile for COD parameter, the minimum loading rate is $1446,61 \mathrm{~kg} / \mathrm{day}$ and in the upstream the minimum COD loading rate $1375,06 \mathrm{~kg} /$ day. For phosphate parameter the loading rate that allowed is $0,79 \mathrm{~kg} /$ day, while in the upstream maximum $12,57 \mathrm{~kg} /$ day on segment 3 .

Keywrods :TukadMati, Qual2KW 5.1, Loading Rate, water quality

\section{PENDAHULUAN}

Kualitas air sungai dipengaruhi oleh kualitas pasokan air yang berasal dari daerah tangkapan sedangkan kualitas pasokan air dari daerah tangkapan berkaitan dengan aktivitas manusia yang ada di dalamnya (Wiwoho, 2005). Masalah utama yang dihadapi oleh sumber daya air meliputi kuantitas air yang sudah tidak mampu memenuhi kebutuhan yang terus meningkat dan kualitas air untuk keperluan domestik yang semakin menurun. (Effendi, 2003).

Tukad Mati merupakan DAS yang menempati wilayah Kabupaten Badung di bagian hulu dan hilir, sementara bagian tengahnya melintasi Kota Denpasar (BLH Kabupaten Badung, 2013). Selain berfungsi sebagai pemenuhan kebutuhan air, khususnya untuk air irigasi, Tukad Mati juga berfungsi sebagai drainase induk (main drain) dari beberapa anak sungai berupa pangkung (sungai musiman) maupun saluran drainase (collector drain) yang menyalurkan air buangan dari kawasan sekitarnya baik dari permukiman maupun dari areal pertanian (Daerah Irigasi Mambal) maupun kawasan pariwisata yaitu mulai dari Desa Ubung Kaja sampai dengan kawasan pariwisata Kuta (BWS-BP,
2011).Dilihat dari fungsinya Tukad Mati telah mengalami penurunan kualitas, karena terkontaminasi limbah domestik, persawahan dan komersial.Beberapa parameter pencemar yang telah melampaui baku mutu yaitu: BOD, COD, Fosfat, dan Total coliform (BLH Provinsi Bali, 2013; BLH Kabupaten Badung 2013).Untuk mencapai tingkat kualitas air Tukad mati sesuai Baku Mutu Kualitas Air Berdasarkan Kelas Air (Peraturan Gubernur Provinsi Bali No. 16 Tahun 2016), maka perlu upaya pengelolaan. Salah upaya untuk pengelolaan Tukad Mati dengan menetapkan daya tampung beban pencemar. Beban pencemar air sungai di Tukad Mati dapat ditentukan dari sumber pencemarnya point source dan non point sourceyang di modelkan dengan program Qual2kw.Penentuan daya tampung beban pencemaran dengan program Qual2Kw lebih efesien karena dapat memodelkan kualitas air sungai dari hulu ke hilir, dapat mensimulasikan parameter dengan maksimal maupun minimal sesuai dengan baku mutu yang berlaku untuk kualitas badan air. (Irsanda,et al., 2014). Penelitian ini bertujuan untuk mengaplikasikan program Qual2kw untuk menghitung daya tampung beban pencemar Tukad Mati yang terbagi dalam simulasi 4 skenario. 


\section{METODOLOGI}

\subsection{Penentuan Wilayah Studi}

Penelitian ini dilakukan di sungai Tukad Mati yang masuk di wilayah Kecamatan Kuta yang terbagi kedalam 3 desa yaitu Seminyak, Legian dan Kuta Waktu penelitian dilakukan bulan Maret- Juni2015 yang dibagi kedalam 3 segmen dengan panjang sungai $5,35 \mathrm{~km}$.

\subsection{Pengumpulan Data}

Data yang di gunakan dalam penelitian ini berupa data primer dan data sekunder. Data primer di peroleh saat survei lapangan yang meliputi lebar sungai, kedalaman sungai, kecepatan arus, debit sungai, sumber pencemar dan kualitas air hasil sampling. Pengukuran debit dilakukan dengan Velocity Method. Pada metode ini, debit (Q) suatu aliran diperoleh sesuai persamaan (1) dan (2): (Sugiharto, 2014).

$\mathrm{Q}=\mathrm{V} \times \mathrm{A}$

$$
\begin{aligned}
& \text { Dimana: } \\
& \begin{aligned}
\mathrm{Q} & =\text { debit aliran }\left(\mathrm{m}^{3} / \text { detik }\right) \\
\mathrm{V} & =\operatorname{Kecepatan} \text { aliran }(\mathrm{m} / \text { detik }) \\
\mathrm{A} & =\text { luas penampang basah }\left(\mathrm{m}^{2}\right) \\
& =\text { lebar sungai X Kedalaman sungai }
\end{aligned}
\end{aligned}
$$

Pengambilan sampel dilakukan dengan dua cara, yaitu pemeriksaan in situ meliputi $\mathrm{pH}$ dan temperatur. Pengukuran Sampel air sungai untuk parameter, BOD, COD dan Fosfat di analisa ke Laboratorium Analitik Universitas Udayana. Data sekunder meliputi peta administrasi, data jumlah penduduk 5 tahun terakhir, data kualitas air dari BLH Kabupaten Badung, dan BLH Provinsi Bali sedangkan data klimatologi di peroleh dari BMKG Wilayah III Denpasar.

\section{HASIL DAN PEMBAHASAN}

Daya tampung beban pencemar dapat ditentukan dengan melalukan berbagai tahapan:

\subsection{Pembagian Segmen Sungai}

Segmentasi sungai diperlukan untuk memudahkan dalam menentukan titik sampling, pembagian segmen didasarkan adanya beban pencemar yang masuk ke badan air tukad mati yang terbagi dalam 3 segmen dapat dilihat pada Gambar 1.

\subsection{Pembangunan Verifikasi Model atau Kalibrasi Data}

Langkah penggunaan model Qual2kw dengan mengentry data primer dan data sekunder pada lembar kerja Qual2kw.Dilanjutkan dengan verifikasi

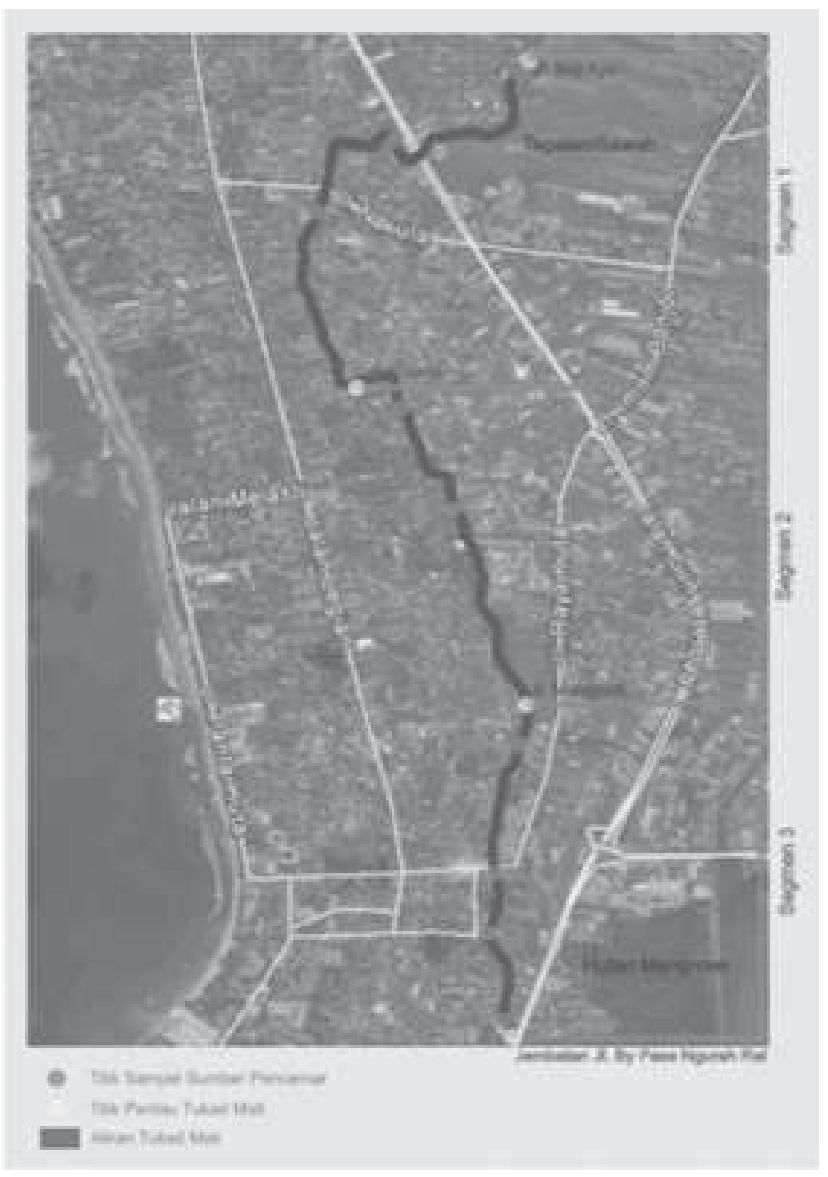

Gambar 1.Pembagian segmenTukad Mati

model atau kalibrasi data yang bertujuan untuk memperoleh data model sesuai dengan data sebenarnya lalu dilanjutkan dengan analisis data pada program Qual2kw (Irsanda et al, 2014).

\subsection{Simulasi Kualitas Air}

Skenario simulasi dibagi menjadi 4 model untuk mendapatkan daya tampung beban pencemar. Teknik simulasi dapat dilihat pada Tabel 1.

\section{Simulasi skenario 1}

Simulasi pada skenario 1 merupakan simulasi dengan kondisi eksisting baik pada kualitas air di sungai maupun data sumber pencemar, dimana data yang diinput sesuai dengan hasil dari pembentukan model. Hasil dari model simulasi skenario 1 tiap parameter dapat dilihat pada Gambar 2, 3 dan 4.

Berdasarkan hasil simulasi skenario 1, kandungan parameter BOD dari hulu hingga hilir dan Fosfat dari jarak 4,26 hingga ke bagian hilir berada diatas baku mutu air Kelas II, yaitu baku mutu parameter BOD sebesar $3 \mathrm{mg} / \mathrm{L}$ dan baku mutu parameter fosfat sebesar 0,2 mg/L. Sedangkan untuk parameter COD, kandungan COD pada Tukad Mati tidak melebihi batas ambang baku mutu yang diijinkan. 
Tabel 1.Skenario Teknik Simulasi

\begin{tabular}{lllll}
\hline No & Kondisi di Hulu & Data Sungai & Sumber Pencemar & Kondisi Air Sungai \\
\hline 1 & Eksisting & Eksisting & Eksisting & Model \\
2 & Eksisting & Eksisting & TidakAda sumber pencemar & Model \\
3 & Eksisting & Eksisting & Estimasi tahun 2020 & Model \\
4 & Eksisting & Baku Mutu Air Kelas II & Trial and error & Baku mutu Air Sasaran Kelas II \\
\hline
\end{tabular}

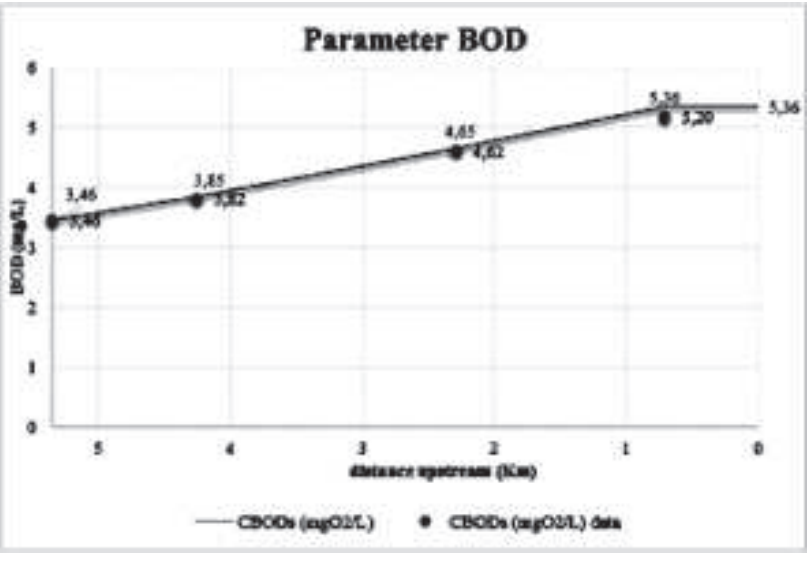

Gambar 2.Simulasi Skenario 1 Parameter BOD

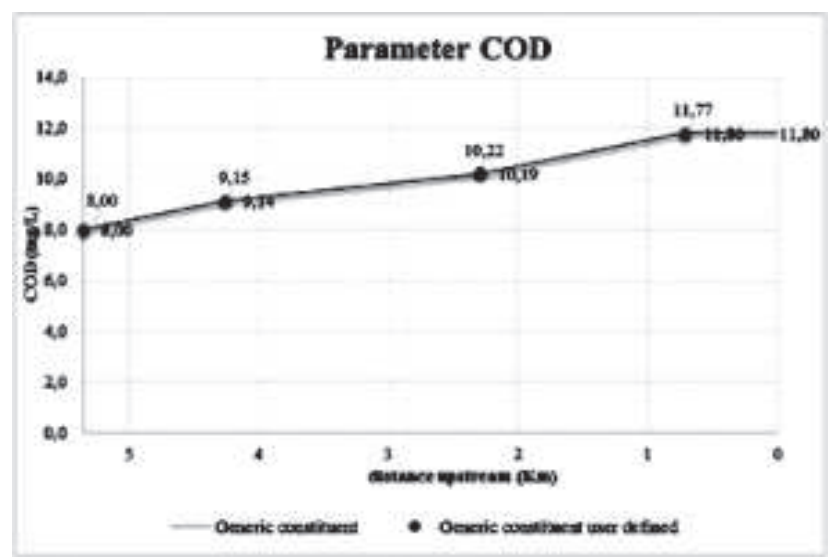

Gambar 3.Hasil Simulasi Skenario 1 Parameter COD

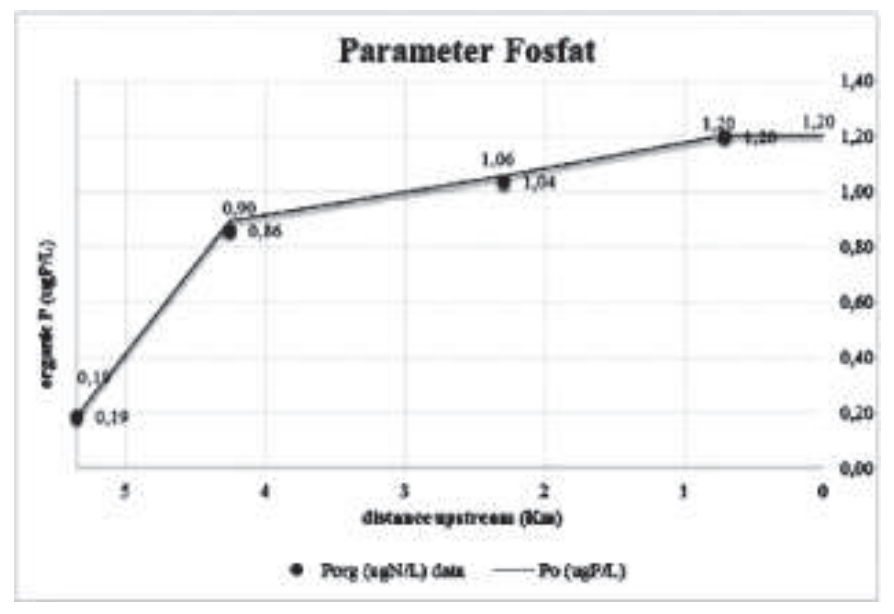

Gambar 4. Simulasi Skenario 1 Parameter Fosfat

Simulasi Skenario 2

Pada skenario ini kualitas air di Tukad Mati menggunakan data existing, sementara itu diasumsikan tidak ada sumber pencemar yang masuk ke Tukad Mati, baik limbah industri maupun limbah domestik. Hasil dari model simulasi skenario 2 tiap parameter dapat dilihat pada Gambar 5, 6 dan 7. Simulasi skenario 2 adalah kualitas badan air dari hulu hingga hilir dikondisikan tidak tercemar oleh sumber pencemar baik point source maupun non point source. Kondisi di hulu diasumsikan tetap disesuaikan dengan kondisi eksisting.

Hasil simulasi skenario 2 pada gambar 5kandungan parameter BOD di bagian hulu sebesar 3,46 mg/L masih berada diatas baku mutu air Kelas II yaitu sebesar $3 \mathrm{mg} / \mathrm{L}$. Sedangkan untuk parameter Fosfat (Gambar7), di semua titik pantau berada di bawah baku mutu air Kelas II yaitu sebesar 0,2 mg/ L. Sedangkan untuk parameter COD (gambar 6), kandungan COD pada Tukad Mati tidak melebihi batas ambang baku mutu yang diijinkan.

\section{Simulasi Skenario 3}

Estimasi sumber pencemar tak tentudidapatkan dengan memperhitungkan pertumbuhan penduduk selama 5 (lima) tahun dari tahun 2015 sampai dengan 2020 sehingga jumlah beban pencemar dari rumah tangga bertambah, baik yang masuk melalui saluran air, drainase dan anak sungai ataupun yang langsung masuk ke Tukad Mati sebagai non-pointsource. Sementara itu jumlah beban pencemar dari industri, perumahan, hotel, dan pertanian diasumsikan tidak bertambah sebagaimana pada skenario 1. Kualitas air sungai menggunakan data eksistingtahun2015. 


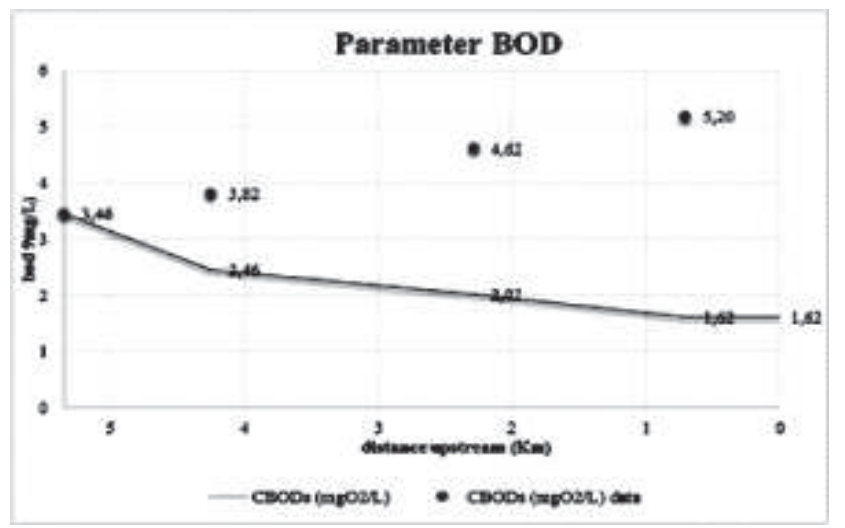

Gambar 5.Simulasi Skenario 2 Parameter BOD

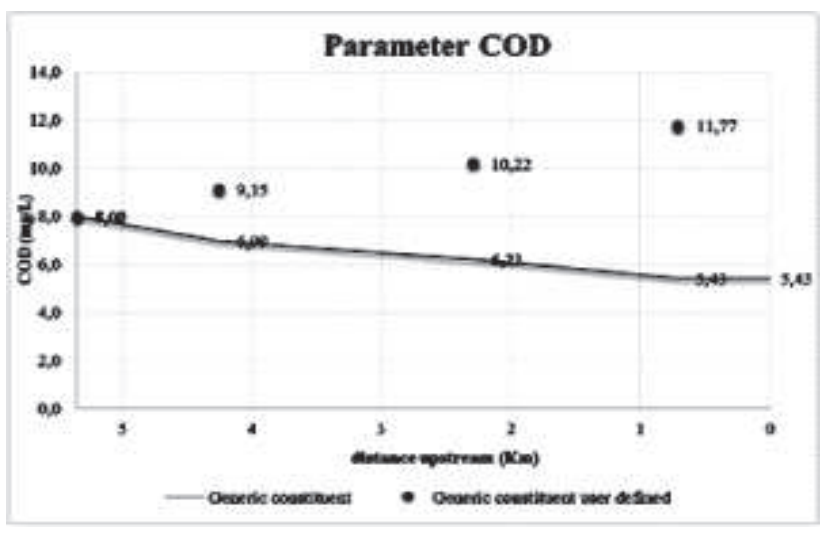

Gambar 6. Simulasi Skenario 2 Parameter COD

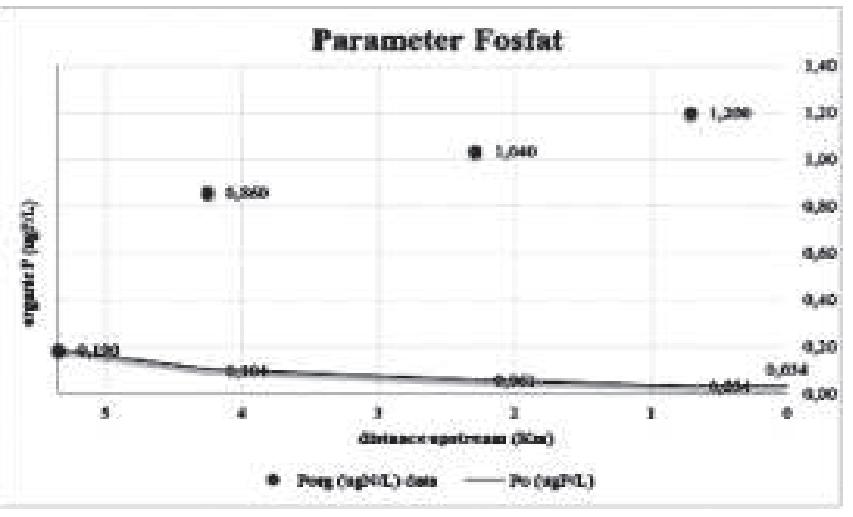

Gambar 7. Simulasi Skenario 2 Parameter Fosfat

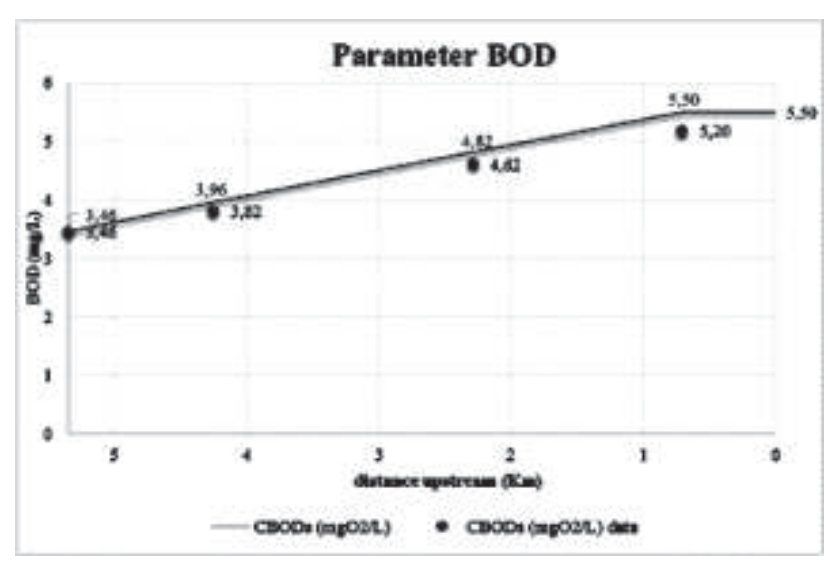

Gambar 8.Simulasi Skenario 3 Parameter BOD

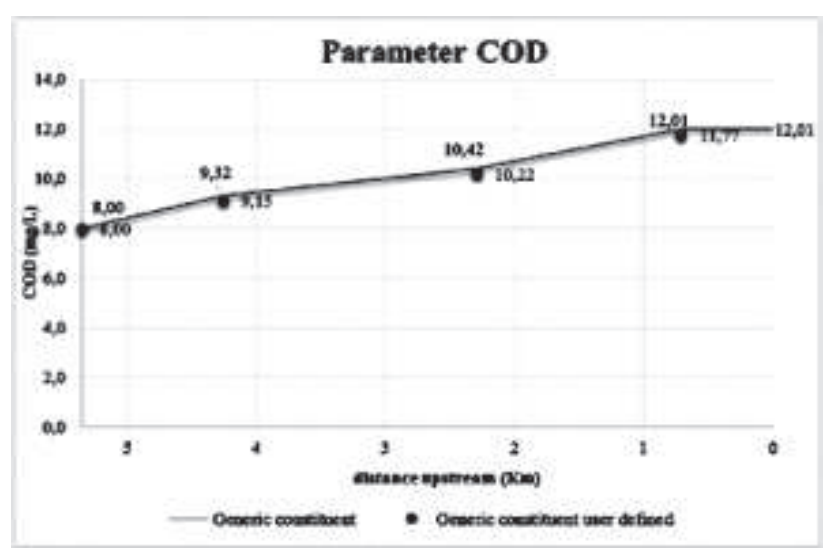

Gambar 9. Simulasi Skenario 3 Parameter COD

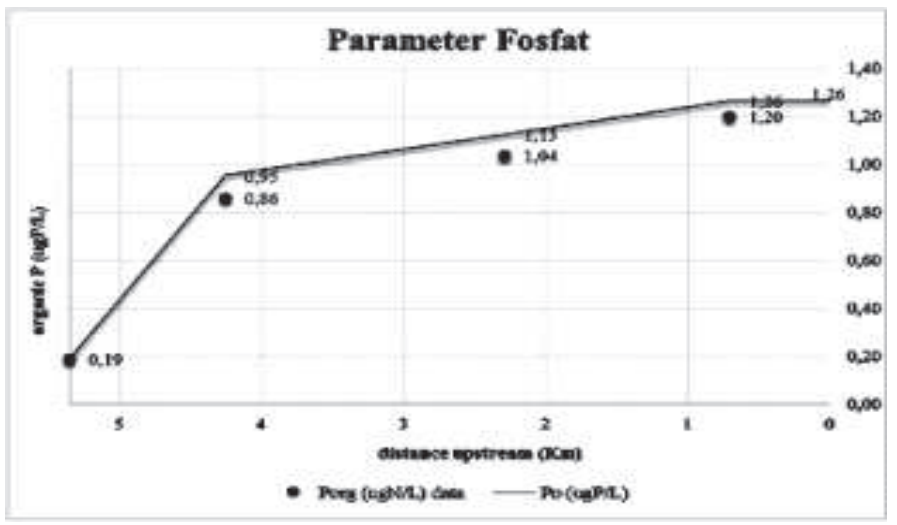

Gambar 10. Simulasi Skenario 3 Parameter Fosfat 
Selanjutnya Kelurahan Seminyak, Legian, dan Kuta dihitung berdasarkan pada proyeksi pertambahan jumlah penduduk dengan berdasarkan persentase pertambahan penduduk sebesar 2,7\% (Kecamatan Kuta Dalam Angka 2016). Pada Kelurahan Seminyak dengan jumlah penduduk 4.018 jiwa (tahun 2020) dan debit limbah 0,486 $\mathrm{m}^{3} /$ detik, Legian dengan jumlah penduduk 4.817 jiwa dan debit limbah 0,732 m³/detik dan Kuta dengan jumlah penduduk 20.599 jiwa dan debit limbah 1,451 m³/detik. Hasil dari model simulasi skenario 3 tiap parameter dapat dilihat padaGambar 8, 9 dan 10 .

Dilihat dari hasil simulasi skenario 3 pada gambar 8 dan 10, kandungan parameter BOD dari hulu hingga hilir dan Fosfat dari jarak 4,26 km hingga ke bagian hilir berada diatas baku mutu air Kelas II, yaitu baku mutu parameter BOD sebesar 3 $\mathrm{mg} / \mathrm{L}$ dan baku mutu parameter fosfat sebesar 0,2 $\mathrm{mg} / \mathrm{L}$. Sedangkan untuk parameter COD (Gambar 9), kandungan COD pada Tukad Mati tidak melebihi batas ambang baku mutu yang diijinkan.

\section{Simulasi Skenario 4}

Simulasi skenario 4 adalah sumber pencemar yang masuk pada kondisi telah memenuhi baku mutu lingkungan guna mendapatkan data model sesuai

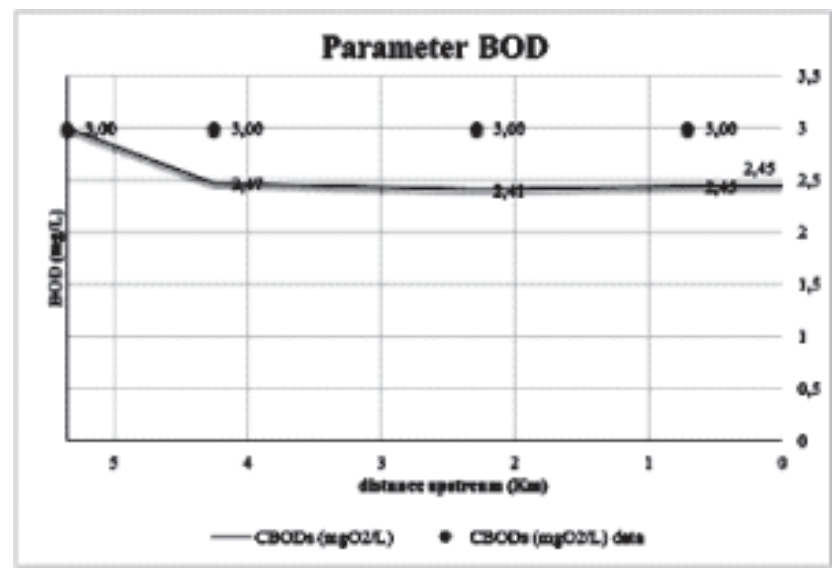

Gambar 11.Simulasi Skenario 4 Parameter BOD dengan baku mutu kelas dua. Selanjutnya agar kondisi kualitas air sesuai dengan baku mutu, dengan cara mengubah-ubah (trial and error) besar konsentrasi parameter dari point source dan non point source. Hasil dari model simulasi skenario 4 tiap parameter dapat dilihat pada Gambar 11, 12 dan 13.

Simulasi skenario 4 adalah kualitas badan air diasumsikan memenuhi baku mutu air kelas II. Kondisi di hulu diasumsikan tetap disesuaikan dengan kondisi eksisting. Sedangkan untuk besar konsentrasi sumber pencemar dilakukan trial and error hingga didapatkan kualitas air dari sungai memenuhi baku mutu air kelas II. Dari hasil simulasi skenario 4 yang ditunjukkan pada Gambar 11, 12 dan 13 dapat disimpulkan bahwa adanya peningkatan kualitas air Tukad Mati dan sudah memenuhi hasil akhir model, yaitu memenuhi baku mutu air kelas II.

\subsection{Perhitungan Daya Tampung Beban Pencemaran. \\ Perhitungan daya tampung merupakan} perhitungan selisih antara kondisi sungai dengan beban pencemar penuh (skenario 4) dan kondisi sungai dengan tanpa beban pencemar yang masuk

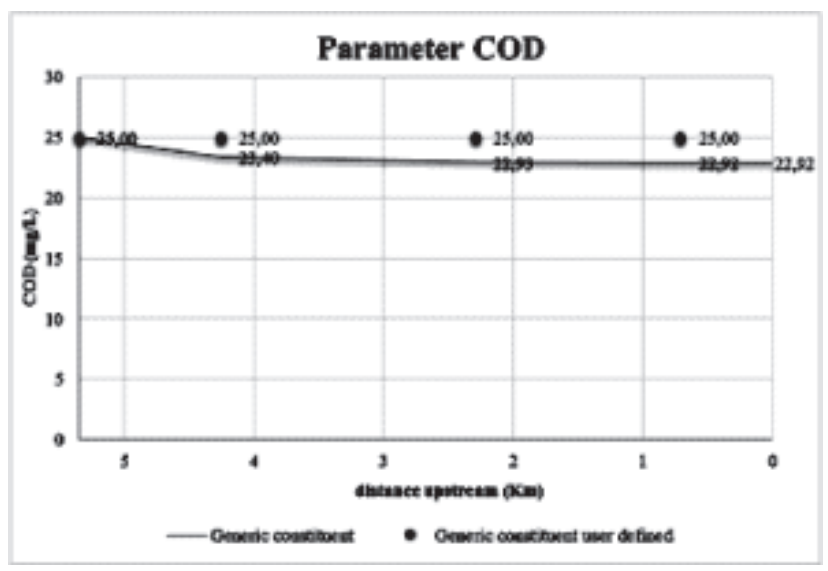

Gambar 12.Simulasi Skenario 4 Parameter COD

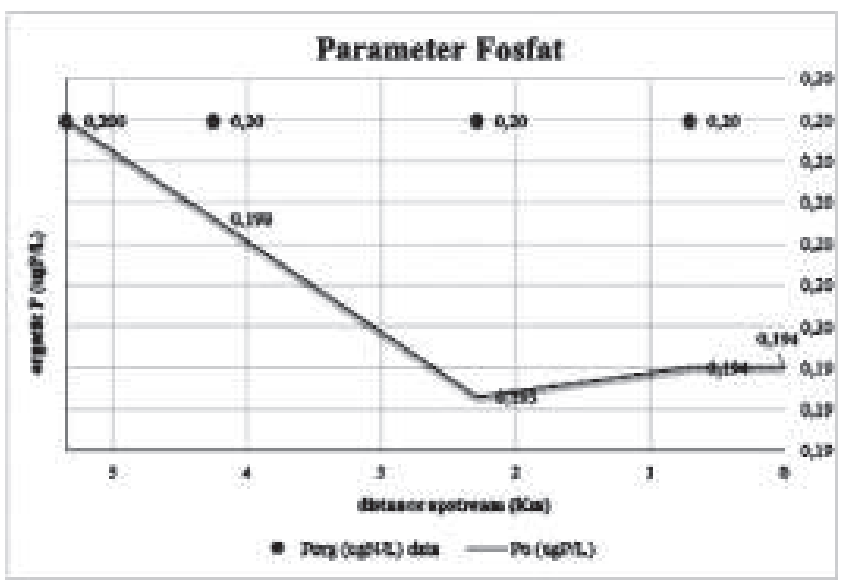

Gambar 13.Simulasi Skenario 4 Parameter Fosfat 
(skenario 2). Pada skenario 2 merupakan kondisi sungai tanpa adanya beban pencemaran dengan menghilangkan semua masukan sumber pencemar. Sedangkan simulasi skenario 4 merupakan kondisi beban pencemaran yang dikondisikansesuai dengan baku mutu sungai kelas II. Perhitungan dapat ditulis dengan rumus sebagai berikut:

Daya Tampung $=$ Beban Pencemar Penuh - Beban Kondisi Awal

Contoh perhitungan beban pencemaran pada skenario 2 sebagai berikut:

$\mathrm{BP}=$ Debit $(\mathrm{L} /$ detik $) \times$ Konsentrasi $(\mathrm{mg} / \mathrm{l})$

$=($ Beban Pencemaran $(\mathrm{mg} / \mathrm{L})$ $\mathrm{x}$ 86.400): 100.000

Debit $=0,91 \mathrm{~m}^{3} / \mathrm{detik}=910 \mathrm{~L} / \mathrm{detik}$

Beban Pencemar BOD = Debit x Konsentrasi

Skenario $2=910 \mathrm{~L} /$ detik $\times 3,46 \mathrm{mg} / \mathrm{l}$

Beban Pencemar $=3148,6 \mathrm{mg} / \mathrm{detik}=272,04 \mathrm{~kg} / \mathrm{hari}$

Tabel 2. Beban Pencemaran Skenario 2

\begin{tabular}{ccccc}
\hline Segmen & Jarak (km) & $\begin{array}{c}\text { BOD } \\
\text { (kg/hari) }\end{array}$ & $\begin{array}{c}\text { COD } \\
\text { (kg/hari) }\end{array}$ & $\begin{array}{c}\text { Fosfat } \\
\text { (kg/hari) }\end{array}$ \\
\hline Hulu & 5,35 & 272,04 & 628,99 & 14,94 \\
Segmen 1 & 3,16 & 193,37 & 549,88 & 8,20 \\
Segmen 2 & 1,42 & 158,82 & 489,67 & 4,77 \\
Segmen 3 & 0 & 127,40 & 427,23 & 2,69 \\
\hline
\end{tabular}

Dilihat dari beban pencemar dari skenario 2, berdasarkan Peraturan Gubernur Nomor 16 Tahun 2016 tentang Baku Mutu Lingkungan Hidup dan Kriteria Baku Kerusakan Lingkungan Hidup pada Lampiran I, maka untuk parameter COD dan Fosfat termasuk dalam kualitas air Kelas I pada setiap segmen, sedangkan untuk parameter BOD, pada bagian hulu termasuk dalam kualitas air Kelas III, pada segmen 1 termasuk dalam kualitas air Kelas II dan untuk segmen 2 dan segmen 3 termasuk dalam kualitas air Kelas I.

Tabel 3. Beban Pencemaran Skenario 4

\begin{tabular}{ccccc}
\hline Segmen & Jarak (km) & $\begin{array}{c}\text { BOD } \\
\text { (kg/hari) }\end{array}$ & $\begin{array}{c}\text { COD } \\
\text { (kg/hari) }\end{array}$ & $\begin{array}{c}\text { Fosfat } \\
\text { (kg/hari) }\end{array}$ \\
\hline Hulu & 5,35 & 235,87 & 1965,60 & 15,72 \\
Segmen 1 & 3,16 & 194,52 & 1839,41 & 15,54 \\
Segmen 2 & 1,42 & 189,72 & 1803,21 & 15,20 \\
Segmen 3 & 0 & 192,29 & 1802,29 & 15,25 \\
\hline
\end{tabular}

Tabel 4. Daya Tampung Beban Pencemaran Tukad Mati

\begin{tabular}{ccccc}
\hline Segmen & Jarak (km) & $\begin{array}{c}\text { BOD } \\
\text { (kg/hari) }\end{array}$ & $\begin{array}{c}\text { COD } \\
\text { (kg/hari) }\end{array}$ & $\begin{array}{c}\text { Fosfat } \\
\text { (kg/hari) }\end{array}$ \\
\hline Hulu & 5,35 & $-36,17$ & 1336,61 & 0,79 \\
Segmen 1 & 3,16 & 1,15 & 1289,52 & 7,34 \\
Segmen 2 & 1,42 & 30,90 & 1313,54 & 10,43 \\
Segmen 3 & 0 & 64,88 & 1375,06 & 12,57 \\
\hline
\end{tabular}

Hasil perhitungan daya tampung beban pencemaran maka dapat diketahui daya tampung minimum dan maksimum tiap parameter. Untuk parameter BOD daya tampung minimum sebesar $1,15 \mathrm{~kg} / \mathrm{hari}$ pada segmen 1 sedangkan maksimum $64,88 \mathrm{~kg} /$ hari pada segmen 3 . Sedangkan untuk parameter COD, daya tampung minimum sebesar $1336,61 \mathrm{~kg} / \mathrm{hari}$ pada bagian hulu sedangkan maksimum 1375,06 kg/hari pada segmen 3 . Untuk parameter fosfat, daya tampung minimum sebesar $0,79 \mathrm{~kg} /$ hari pada bagian hulu sedangkan maksimum $12,57 \mathrm{~kg} / \mathrm{hari}$ pada segmen 3 . Tukad Mati sudah tidak mempunyai daya tampung beban pencemar parameter BOD pada bagian hulu Tukad Mati, sehingga perlu dilakukan upaya untuk menurunkan beban pencemar di Tukad Mati wilayah Kabupaten Badung khususnya bagian yang menjadi hulu pada penelitian ini.

\section{SIMPULAN DAN SARAN}

\subsection{Simpulan}

Berdasarkan hasil penelitian dan pembahasan dapat disimpulkan beberapa hal yaitu:

1. Beban Pencemar di Tukad Mati adalah sebagai berikut:

a. Parameter BOD beban pencemar untuk skenario 2 beban pencemar terbesar sebesar $193.37 \mathrm{~kg} / \mathrm{hari}$ pada segmen 1 dan terkecil $127.40 \mathrm{~kg} /$ hari pada segmen 3 , dan untuk skenario 4 beban pencemar terbesar sebesar $194.52 \mathrm{~kg} / \mathrm{hari}$ pada segmen 1 dan terkecil $189.72 \mathrm{~kg} /$ hari pada segmen 2

b. Parameter COD beban pencemar untuk skenario 2 beban pencemar terbesar sebesar $549.88 \mathrm{~kg} / \mathrm{hari}$ pada segmen 1 dan terkecil $427.23 \mathrm{~kg} /$ hari pada segmen 3 , dan untuk skenario 4 beban pencemar terbesar sebesar $1839.41 \mathrm{~kg} / \mathrm{hari}$ pada segmen 1 dan terkecil $1802.29 \mathrm{~kg} /$ hari pada segmen 3

c. Parameter Fosfat beban pencemar untuk skenario 2 beban pencemar terbesar sebesar $8.20 \mathrm{~kg} /$ hari pada segmen 1 dan terkecil 2.69 $\mathrm{kg} /$ haripada segmen 3, dan untuk skenario 4 beban pencemar terbesar sebesar $15.54 \mathrm{~kg} /$ hari pada segmen 1 dan terkecil $15.20 \mathrm{~kg} /$ hari pada segmen 2

2. Daya tampung beban pencemaran di Tukad Mati untuk tiap parameter terbagi menjadi daya tampung maksimum dan minimum sebagai berikut:

a. Parameter BOD daya tampung minimum sebesar $1,15 \mathrm{~kg} / \mathrm{hari}$ pada segmen $1 \mathrm{dan}$ maksimum 64,88 kg/hari pada segmen 3, sedangkan pada bagian hulu sudah tidak mempunyai daya tampung beban pencemar.

b. Parameter COD daya tampung minimum sebesar 1336,61 kg/hari pada bagian hulu 
dan maksimum $1375,06 \mathrm{~kg} /$ hari pada segmen 3.

c. Parameter Fosfat daya tampung minimum sebesar $0,79 \mathrm{~kg} /$ hari pada segmen 1 dan maksimum $12,57 \mathrm{~kg} / \mathrm{hari}$ pada segmen 3.

\subsection{Saran}

1. Adanya kajian daya tampung beban pencemaran yang lebih lanjut di Tukad Mati dengan penambahan simulasi skenario, parameter yang dianalisis, dan analisis pada kondisi kualitas air yang berbeda seperti simulasi kualitas air dengan kondisi air Tukad Mati pada saat musim kemarau dan musim hujan.

2. Diperlukannya upaya pengendalian pencemaran air Tukad Mati dengan memperhatikan kondisi kualitas air serta masyarakat ataupun kegiatan yang ada di sekitar aliran Tukad Mati

\section{DAFTAR PUSTAKA}

Badan Lingkungan Hidup Provinsi Bali. 2013. Hasil Pemantauan Kualitas Air Tahun 2013.Provinsi Bali
Badan Lingkungan Hidup Kabupaten Badung. 2013. Penetapan Daya Dukung Beban Pencemar Sungai Tukad Mati dan Sungai Tukad Bangiang Tahun 2013. Kabupaten Badung

Balai Wilayah Sungai Nusa Penida, 2011. Analisa Kelayakan Teknis Penanganan Tukad Mati

Effendi, H. 2003. Telaah Kualitas Air Bagi Pengelolaan Sumber daya dan Lingkungan Perairan. Kanisius. Yogyakarta.

Irsanda et al, 2014. Analisis Daya Tampung Beban PencemaranKali Pelayaran Kabupaten Sidoarjo Dengan Metode Qual2kw. Jurnal Teknik Pomits Vol. 3, No. 1, (2014) ISSN: 2337-3539

Sugiharto, 2014. Kajian Total Daya Tampung Beban Pencemaran Harian Menggunakan Permodelan Qual2k Untuk Pencemar BOD, TSS, Ammonia, Fosfat dan Nitrat di Sungai Kampung Bugis, Tarakan. Jurnal Manusia dan Lingkungan, Vol. 21, No.1, Maret 2014: 21-29

Wiwoho.2005."Model Identifikasi Daya Tampung Beban Cemaran Sungai dengan Qual2E" (tesis).Semarang:Universitas Diponegoro. 